\title{
Avaliação Psicológica em Concursos Públicos e Porte de Arma: Histórico e Desafios
}

\author{
Cristiane Faiad ${ }^{1}$ \\ ${ }^{1}$ Universidade de Brasília, DF, Brasil. \\ Andersson Pereira dos Santos ${ }^{2}$ \\ ${ }^{2}$ Polícia Federal, DF, Brasil.
}

Elza Maria Gonçalves Lobosque ${ }^{3}$

${ }^{3}$ Centro Universitário Estácio de Juiz de Fora, MG, Brasil.

\author{
Olavo Sant'Anna Filho ${ }^{4}$ \\ ${ }^{4}$ Conselheiro Nacional da Cruz Vermelha Brasileira, SP, Brasil. \\ Lyani Vieira do Prado \\ ${ }^{5}$ Serviço de Equoterapia, Polícia Militar, São Paulo, SP, Brasil.
}

Francisco Antônio Coelho Junior ${ }^{1}$

${ }^{1}$ Universidade de Brasília, DF, Brasil.

\begin{abstract}
Resumo: Trata-se de um estudo teórico que aborda a avaliação psicológica no contexto de avaliações compulsórias, tanto em concurso público quanto para posse ou porte de arma de fogo. São apresentados os maiores desafios da área, a partir do histórico e da exposição de alguns dos problemas enfrentados na prática, diante das diferentes normativas que regulam este contexto. Na avaliação psicológica em concursos, ressalta-se como um dos maiores desafios a forte influência do poder judiciário nos últimos 60 anos, que inclui a definição ou restrição de procedimentos na atuação do profissional. Quanto à avaliação para porte de arma de fogo, discutem-se as diversas mudanças que ocorreram nos últimos anos e suas implicações. $\mathrm{O}$ texto incentiva os profissionais que atuam na área a refletir sobre as consequências sociais que o resultado dessa avaliação pode trazer. No Brasil, as pesquisas realizadas no contexto de avaliação psicológica compulsória ainda são escassas, o que mostra a necessidade de estudos que contribuam para melhoria nesse campo de atuação. É necessário compreender, inclusive, os impactos que a publicação de normativas e a qualidade da atuação dos profissionais podem provocar, bem como seus efeitos sobre a sociedade como um todo.
\end{abstract}

Palavras-chave: Avaliação Psicológica, Avaliação Compulsória, Concurso Público, Porte de Armas de Fogo, Testes Psicológicos.

\section{Psychological Assessment in Civil Service Entrance Examination and Firearms License: History and Challenges}

\begin{abstract}
This theoretical study addresses psychological assessment in the context of compulsory exams for civil service entrance examination and firearms licenses. By presenting the history and some issues related to regulations, this article presents the greatest challenges in the area of compulsory exams. When it comes to procurement exams, a major challenge accounts for the strong influence of the judiciary over the past 60 years, defining or restricting procedures in professional performance. As for firearms license exams, the article expatiates on several changes that have occurred in recent years, as well as their implications. The text encourages professionals working in the field to reflect upon the social consequences of this assessment results. Studies on compulsory psychological assessment are still scarce in the Brazilian literature, indicating the need for research to improve this field of action. Moreover, one should also consider the impacts of regulations and quality professionals on these assessments and on society as a whole.
\end{abstract}

Keywords: Psychological Assessment, Compulsory Assessment, Civil Service Entrance Examination, Firearms Door, Psychological Tests. 


\title{
Evaluación Psicológica en Competencias y la Portación de Armas: Historia y Desafíos
}

\begin{abstract}
Resumen: Este estudio teórico aborda la evaluación psicológica en el contexto de las evaluaciones obligatorias tanto en concurso público como por posesión o portación de armas de fuego. Se presentan los mayores desafíos del área a partir de la historia y de algunos de los problemas que se enfrentan en la práctica, dadas las diferentes normativas que regulan este contexto. En el contexto de la evaluación psicológica en los concursos públicos, uno de los mayores desafíos es la fuerte influencia del Poder Judicial en los últimos 60 años, que incluye la definición o restricción de procedimientos en el desempeño del profesional. En cuanto a la evaluación para portación de arma de fuego, se discuten los distintos cambios que se han producido en los últimos años y sus implicaciones. El texto anima a los profesionales que trabajan en el área a reflexionar sobre las consecuencias sociales que puede traer el resultado de esta evaluación. En Brasil, la investigación realizada en el contexto de la evaluación psicológica obligatoria es aún escasa, lo que muestra la necesidad de estudios que contribuyan a la mejora en este campo de acción. Incluso es necesario comprender los impactos que puede causar la publicación de normativas y la calidad del desempeño de los profesionales, así como sus efectos en la sociedad en su conjunto.
\end{abstract}

Palabras clave: Evaluación Psicológica, Evaluación Obligatoria, Concurso Público, Portación de Armas de Fuego, Pruebas Psicológicas.

O histórico e a prática da avaliação psicológica compulsória no Brasil são permeados por uma série de desafios teórico-metodológicos. Esses desafios geram, constantemente, questionamentos e reflexões necessárias à atuação profissional neste contexto. Pode-se sumarizá-los da seguinte forma: a falta de compreensão das especificidades dessa avaliação por parte dos profissionais; a implicação de decisões por parte do poder judiciário nas avaliações compulsórias; a construção de diferentes documentos normativos externos à Psicologia que trazem desdobramentos sobre as práticas avaliativas; a escassez de medidas psicológicas validadas que deem conta de sua demanda; e a necessidade de maior qualificação profissional, dentre tantos outros que poderiam ser elencados. São tais desafios que, em menor ou maior grau e complexidade, atuam como potencializadores de distintos impactos e como importantes condicionantes à atuação do psicólogo. Um ponto fundamental das avaliações compulsórias está no entendimento do seu contexto e no fato de essa prática não se limitar apenas a normas e orientações da ciência psicológica, mas envolver outros fatores e elementos que serão discutidos adiante.

A avaliação psicológica consiste em um processo complexo, de cunho científico, que integra o conheci- mento técnico e a análise de uma conjunção de dados confiáveis (American Psychological Association, 2001) advindos da aplicação de diferentes métodos e técnicas. Seu resultado permite a tomada de decisões ou a indicação de recomendações para questões psicológicas de indivíduos, grupos ou instituições (American Psychological Association, 2001, 2020; Conselho Federal de Psicologia, 2019).

Por sua concepção técnica e pelo potencial impacto que pode causar na vida das pessoas, é necessário que o profissional que atua no campo detenha competências, conhecimentos, habilidades, treinamento, experiência e credenciamento específicos (American Psychological Association, 2001; Nunes et al., 2012) ao lidar com técnicas e métodos psicológicos. Esses elementos são importantes, afinal, um profissional devidamente qualificado protege a pessoa avaliada, dado sua competência para prestar um serviço ético e de qualidade, provendo o devido suporte, especialmente na etapa devolutiva dos resultados (American Psychological Association, 2020).

Visto que a Psicologia abarca diferentes áreas de atuação - que exigem do profissional psicólogo compreensão teórica sobre manifestações do comportamento e do desenvolvimento humano, da persona- 
lidade e da psicopatologia, dentre outras temáticas implicadas em uma avaliação -, o uso de medidas psicológicas também irá requerer tanto o conhecimento sobre as questões éticas implicadas no uso das medidas quanto conhecimentos sobre psicometria (Evans \& Finn, 2016; Muniz, 2017). Isso significa dizer que, a depender do contexto de atuação, é necessário o desenvolvimento de competências técnicas específicas, não gerais (American Psychological Association, 2020). Este último ponto abre uma importante discussão reflexiva. Se as avaliações compulsórias estão inseridas em um contexto específico da avaliação psicológica, então são requeridas competências técnicas específicas para sua atuação. Neste sentido, um psicólogo que venha a atuar nessa área deve dominar este contexto. Apenas assim atuará conforme os padrões éticos e aplicará seu conhecimento técnico-científico em prol do alcance dos melhores resultados em sua prática.

O conceito de avaliação compulsória tem sido utilizado de forma indiscriminada em dois tipos de contextos. Apesar de aplicarmos a mesma terminologia, por ambas terem um caráter obrigatório, por demandarem uma avaliação ou previsão de um comportamento, há importantes diferenças entre elas: o objetivo e as consequências para aquele que se submete a esta. Uma delas tem um sentido mandatório, trata-se de uma avaliação involuntária, coercitiva (Boyle, Walsh, \& Nelson, 2021; Mathews \& Pratt, 2016; Morel, 2009), uma avaliação pericial, do campo da especialidade da Psicologia Jurídica. Neste caso, a avaliação pericial se constitui em uma prova técnica, que visa dar subsídios para discutir direitos que a princípio a pessoa teria assegurado pela Constituição Federal. Conforme definido no Ofício-Circular no 63/2020/ GTec/CG-CFP (Conselho Federal de Psicologia, 2020): "não é caracterizado pela voluntariedade do avaliando quanto ao procedimento, mas pela coercibilidade da tarefa pericial, já que o objetivo é a produção de provas e resultados avaliativos" (n.p.). A pessoa é obrigada a se submeter a um processo avaliativo, por determinação judicial. Nem sempre está em uma situação que possa negá-la e, se o fizer, pode vir a sofrer um dano, uma perda ou mesmo uma grave punição. Para esta atuação (como, por exemplo, na interdição, guarda paternidade, incapacidade civil, entre outros), que é compulsória, propõe-se identificá-la como uma avaliação psicológica "compulsória mandatória".

No Brasil, o termo "avaliação psicológica compulsória” também é aplicado a outro tipo de contexto.
Neste caso, há uma norma específica (por exemplo, Lei, Decreto, Norma Interna, Resolução, entre outros) que institui e exige sua realização, tornando-a obrigatória como fase de algum processo (Faiad \& Alves, 2018). A pessoa se submete a esta avaliação para que possa obter algum ganho que seja do seu interesse (carteira de habilitação, cargo público, direito a portar arma, entre outros). Neste caso, para se adquirir ou conquistar esse direito, a pessoa precisa comprovar uma capacidade. A obrigatoriedade não é coercitiva, mas uma exigência que deve ser cumprida, vinculada a um processo maior. Caso a pessoa não cumpra essa fase, a consequência é perder a possibilidade de obter esse direito que estava sendo pleiteado. Para essa aplicação, que também é compulsória, propõe-se identificá-la como avaliação psicológica "compulsória normativa”.

Essa diferenciação é importante, porque o presente artigo tem como foco a avaliação psicológica compulsória normativa. Trata-se de uma das avaliações de maior amplitude no país e que anualmente é realizada em milhares de pessoas (Conselho Federal de Psicologia, 2019). Há diferentes tipos de avaliações compulsórias normativas identificadas no Brasil, cada uma definida por uma regra específica. Por isso, não é possível compará-las ou considerá-las como uma mesma avaliação. Ela pode ser identificada em contextos como o de trânsito (Aparecida, Mendes, \& Silva, 2018), concursos públicos (Thadeu, Ferreira, \& Faiad, 2012), cirurgia bariátrica (Walter, Hoyt, Martinez, \& Dziura, 2021), porte de arma de fogo (Hasbun, Formiga, \& Estevam, 2021; Rafalski \& Andrade, 2015), reprodução assistida (Szöke et al., 2018), processo de transplantes de órgãos (Lazzaretti, 2006), aviação civil (Conselho Federal de Psicologia, 2019), entre outras aplicabilidades.

A inclusão de uma avaliação psicológica compulsória normativa se justifica pelo contexto a que ela se insere, já que variáveis psicológicas podem influenciá-lo de alguma forma, mais especificamente no desempenho esperado. Sua aplicação busca resguardar maior segurança à sociedade e ao indivíduo, promovendo menor risco à coletividade e a preservação da saúde pública. A título de exemplo, a avaliação compulsória normativa é aplicada no contexto do trânsito, visto que características psicológicas do motorista podem influenciar a condução de um veículo (Jesuíno \& Rueda, 2017). Aplica-se em pessoas que trabalham em espaço confinado ou altura, por meio de Normas Reguladoras (Rodrigues \& Faiad, 2018), pois, a depender das condições emocionais desses trabalhadores, 
principalmente aqueles que trabalham em ambientes extremos, podem colocar em risco a vida de seus colegas (Driskell, Salas, \& Driskell, 2018). Em concursos públicos para segurança pública, por exemplo, em que o cargo pleiteado está inserido em um contexto estressante e traumático (Gomez et al., 2021), exige-se a adequação a um perfil para o desempenho das atividades do cargo (Faiad, Coelho Junior, Caetano, \& Albuquerque, 2012; Ostapovich et al., 2021).

A especificidade dessa avaliação exige que o profissional psicólogo detenha competência técnica, que atue de forma ética (Muniz, 2018) e que compreenda as implicações de suas ações no indivíduo, em um grupo e na sociedade (Bueno \& Peixoto, 2018). Afinal, ele terá a responsabilidade de indicar aptidão, ou inaptidão, como o resultado de uma avaliação compulsória, atentando-se para as possíveis consequências advindas dessa decisão. Aptidão ou inaptidão relaciona-se ao perfil desejado ou esperado para o desempenho, tomando como referência aquilo que o indivíduo apresenta em termos de comportamentos desejáveis ou esperados. Este perfil é definido previamente por meio de um estudo científico do cargo, antigamente conhecido como análise profissiográfica ou profissiografia (Faiad et al., 2012) e publicado em algum documento formal que orienta a avaliação psicológica na a escolha dos métodos e técnicas avaliativas.

Neste artigo, serão discutidos dois destes contextos: concurso público e obtenção do porte de arma de fogo. A escolha se deve aos indiscutíveis desafios que essas avaliações têm enfrentado nas últimas décadas e sua enorme relevância à prática profissional do psicólogo.

\section{Concurso público}

Há relato de processos seletivos formais já na China Antiga, em 2.200 a.C., quando candidatos pleiteavam vagas a cargos vinculados ao império. Contudo o primeiro concurso público ocorreu na França, na seleção de vagas para cargos públicos durante o governo de Napoleão Bonaparte. Já a testagem psicológica em larga escala para processos seletivos foi registrada na II Grande Guerra, com a aplicação dos testes Army Apha e Beta para seleção de soldados (Gregory, 2015).

No Brasil, as primeiras seleções formais ocorreram no contexto militar, em atendimento ao Decreto $\mathrm{n}^{\circ} 1.860$ de 1908 (Sousa, 2011). Ainda assim, o primeiro concurso público foi realizado em 1937, com a seleção para o Instituto de Aposentadoria e Pensões dos Indus- triários (Iapi), com as fases de prova oral e psicotécnica. Esse processo trouxe a ideia de que deveriam ser aplicados critérios mais técnicos nas seleções de pessoas, contrariamente às práticas de indicações e nomeações até então consolidadas (Hochman, 1988). Em 1938, foi criado o Departamento do Serviço Público (Dasp) como forma de concretizar a mudança na entrada do serviço público por meio de concursos, sob uma lógica de eficiência, impessoalidade e democracia.

Em 1944, foi criada a Fundação Getúlio Vargas (FGV) e, a partir do convite ao professor Mira y López, em 1947, foi fundado o Instituto de Seleção e Orientação Profissional - Isop - (Mancebo, 1999; Martins, 2014), que somou esforços para o avanço na Psicologia prática e na formação técnica de profissionais da área, também atuantes em concurso público.

A Psicologia passou a responder, a partir da Revolução de 1930, aos desafios advindos do processo de industrialização e a receber demandas de recrutamentos e seleções de forma metódica e racional, baseadas na identificação de aptidões e habilidades que otimizassem o processo de trabalho (Mancebo, 1999). Surgiram, portanto, os profissionais denominados psicotécnicos (Esch \& Jacó-Vilela, 2001) ou psicologistas, que, sob a responsabilidade de realizar aplicações de testes no contexto do trabalho, eram compostos por médicos, pedagogos, engenheiros e militares (Mancebo, 1999).

Mais tarde, foi atribuído o termo psicólogo ao profissional técnico que atuava na Psicologia (Schneider, 1955), com formação e exigências técnicas específicas. Tais referências indicam que a prática psicológica antecedeu à própria regulamentação da profissão no Brasil, ocorrida apenas com a promulgação da Lei no 4.119/62 de 27 de agosto (1962) quando, dentre os diferentes campos de atuação, se configurava o que se chamava até então de "psicotécnico".

O ingresso no serviço público brasileiro passou a ser regulamentado pela Constituição Federal de 1988. O Artigo 37 estabeleceu como requisito para investidura nos cargos ou empregos públicos, a prévia aprovação em concurso público, de provas ou de provas e títulos, de acordo com a natureza e a complexidade do cargo ou emprego, na forma prevista em lei, ressalvadas as nomeações para cargo em comissão declarado em lei de livre nomeação e exoneração (Brasil, 1988). É no histórico do concurso público e, consequentemente, da fase da avaliação psicológica, que se elucida qual é o verdadeiro objetivo ou papel atribuído a esta avaliação. 


\section{Objetivo da Avaliação Psicológica do Concurso Público}

Há uma importante diferença entre o real objetivo da avaliação psicológica neste contexto e a expectativa do que é possível atingir neste processo. A avaliação psicológica no contexto de concursos tem como objetivo identificar se um candidato tem o perfil adequado para determinado cargo (Faiad \& Alves, 2018; Faiad et al., 2012; Maia \& Queiroz, 2007; Santos, 2016; Thadeu et al., 2012), de forma a potencialmente apresentar o desempenho mais adequado para ele. Ou seja, não se trata de um processo de psicodiagnóstico para avaliação da condição mental de um candidato.

Insere-se a um tipo ou modelo de seleção de pessoal, na busca pela identificação de indivíduos que venham a atender às demandas de uma organização específica. As demandas organizacionais seriam atendidas, assim, por meio da manifestação de competências comportamentais, técnicas ou requisitos psicológicos possíveis de agregar valor e crescimento à organização, favorecendo o alcance dos resultados esperados no trabalho.

Diferentes terminologias podem ser assumidas a depender do contexto ou instituição, dentre as quais: psicotécnico, avaliação biopsicossocial, psicoteste, avaliação psicossocial, testagem e avaliação psicológica. Considera-se esta última mais adequada, todavia diferenciar a "avaliação" da "testagem" é essencial. Oliveira, Monteiro, Faiad, Muniz e Schelini (2020) explicam que a testagem é um tipo de avaliação psicológica e que se constitui pela aplicação dos testes psicológicos. Já a avaliação lança mão de outras técnicas ou métodos para além dos testes. Então, tem se questionado: por que a maior parte dos concursos se restringe à testagem? Por que há técnicas e métodos que não podem ser utilizados, a depender do certame?

No entendimento da justiça brasileira, de que a aplicação de testes psicológicos é a forma mais justa de se realizar uma avaliação em concurso público (Santos, 2016), essa prática passou a ser a mais comum. Ou seja, não há uma justificativa técnica por parte da Psicologia, já que este entendimento partiu de decisões judiciais, que passaram a intervir na prática dos psicólogos que atuam neste contexto.

\section{O papel do Judiciário e sua influência na avaliação psicológica dos concursos}

Enquanto um dos principais procedimentos utilizados em processos seletivos para ingresso em cargos públicos, a avaliação psicológica é a etapa que, mais frequentemente, tem sido objeto do crivo do poder judiciário. Isso acontece por conta de ações judiciais impetradas por candidatos não recomendados ou considerados inaptos em concursos públicos, mas que buscam a sua reintegração nos certames e a posse nos cargos a empregos públicos para os quais concorreram. Muitos entram com mandados de segurança durante andamento do concurso, visando permanecer no certame, mesmo não tendo sido recomendados/aptos durante a etapa de avaliação psicológica.

Apesar do registro de decisões favoráveis à avaliação psicológica, nos últimos 30 anos, a jurisprudência brasileira tem sido ampla e repetidamente favorável aos candidatos, determinando o ingresso de candidatos não recomendados/inaptos em avaliações psicológicas. Além de desconsiderar o resultado da avaliação psicológica, ainda mais preocupante tem sido a restrição da utilização de técnicas psicológicas em concursos públicos. Cite-se, por exemplo, o veto às entrevistas (vide o Agravo Regimental no Recurso Extraordinário no 344.880 do Superior Tribunal Federal [STF] e o Recurso Especial no 11.087 de 26 de junho de 1991 do Superior Tribunal de Justiça [STJ]), às dinâmicas de grupo e aos testes projetivos (vide Recurso Especial $\mathrm{n}^{\circ} 763.573$ de 19 de outubro de 2009 pelo STF), a despeito da importância de tais fontes fundamentais (Conselho Federal de Psicologia, 2018) para a avaliação dos candidatos.

Tais exemplos evidenciam que a intervenção da justiça em avaliações psicológicas ocorre há mais de 60 anos. Afinal, conforme registrado por Santos (n.d), o primeiro acórdão do STF que trata de avaliação psicológica foi proferido nos autos do Recurso em Mandado de Segurança no 5.972, julgado em 10 de novembro de 1958, anulando a decisão de uma avaliação realizada em 1949 em prol de um candidato. Nesse sentido, a Ação Direta de Inconstitucionalidade (ADI) no 3.481 (Supremo Tribunal Federal, 2021) publicada em 16 de março de 2021, que torna inconstitucional o disposto na Resolução do CFP no 2/2003 (Conselho Federal de Psicologia, 2003), no que tange à restrição da comercialização e uso de testes psicológicos aos psicólogos, vem a somar-se a uma série histórica de decisões que trouxeram consequências importantes para o fazer científico da avaliação psicológica.

Não se pode negar que essa decisão trouxe um grande impacto técnico e social à Psicologia enquanto ciência e profissão. Houve a quebra de importan- 
tes princípios constitucionais que regem o concurso público, como o princípio da isonomia, da impessoalidade e da equidade. Ainda, se uma pessoa sem formação em Psicologia acessar os testes psicológicos, não terá competência técnica para utilizá-lo de forma adequada. Pois, como discutido neste artigo, o uso de instrumentos psicológicos requer competências técnicas específicas. Se mal manuseados ou utilizados, podem colocar em risco a vida do indivíduo ou de outrem, por exemplo, na tentativa de burlarem requisitos psicológicos que um candidato não detém, mas que tenta alcançá-los por meio do estudo prévio de documentos técnicos. $\mathrm{O}$ treino às respostas a um determinado teste poderá ser prática comum, por exemplo, colocando em xeque a própria credibilidade e legitimidade do certame público.

Esta não será uma consequência que atingirá apenas os concursos públicos, mas poderá impactar na sociedade como um todo, afinal, todo e qualquer cidadão tem perfil para portar uma arma de fogo, por exemplo? Facilitar o acesso a pessoas sem conhecimento técnico, aos instrumentos científicos utilizados para análise de perfil para portar arma de fogo, pode estimular a que pessoas despreparadas tenham acesso a tal porte?

\section{Avaliação para porte de arma de fogo}

Na contramão de importantes discussões nacionais e internacionais de que a ampla liberação do uso de armas de fogo não diminuiu a criminalidade, o Brasil tem caminhado para uma tentativa de armar sua população. Aqui não se pretende fazer juízo de valor sobre este fato, mas apontam-se implicações que isso pode ocasionar. A questão é preocupante, especialmente quando pesquisadores de países como a Ucrânia, que enfrenta desafios relacionados à criminalidade, apontam que mesmo alguns profissionais treinados e especializados podem ter dificuldade com o uso adequado da arma, quando necessário (Ostapovich et al., 2021). Tal dado evidencia a importância da avaliação identificar se um indivíduo está apto ou não a portá-la, atentando-se para um perfil mínimo necessário. Mas, afinal, qual o histórico de normativas que definem essa avaliação e quais os maiores desafios nessa área?

A realidade (e as desigualdades) sociocultural, bem como o próprio temperamento do brasileiro e o sentimento comum de impunidade podem ser importantes condicionantes à determinação de polí- ticas públicas de porte de armas. Estas variáveis, conjuntamente com outras, precisam ser consideradas simultaneamente. $\mathrm{O}$ acesso a testes psicológicos por parte de qualquer cidadão, independentemente de ser ou não psicólogo, também entra como variável importante que pode agravar esse cenário.

O primeiro documento a ditar as regras sobre fabricação e circulação de armas e munições foi $o$ Decreto no 24.602, de 6 de julho de 1934, assinado por Getúlio Vargas, que, mais tarde, foi regulamentado pelos Decretos no 1.246, de 11 de dezembro de 1936 e 47.587, de 4 de janeiro de 1960 . O primeiro documento proibia a fabricação de armas e munições de guerra por empresas particulares, permitindo somente a fabricação de armas e munição de caça, sem fazer qualquer menção às armas de uso civil. Outros Decretos sucederam os primeiros documentos, como o Decreto $\mathrm{n}^{\circ}$ 55.649, de 28 de janeiro de 1965, que tinha como objetivo incentivar abertamente a indústria armamentista brasileira.

Somente em 1980 foi promulgada a primeira norma brasileira que trata especificamente da aquisição e do registro de armas por civis. A Portaria Ministerial $\mathrm{n}^{\circ} 1.261$, de 11 de outubro de 1980 (Ministério da Justiça, 1980), estabelecia que cada cidadão poderia ser proprietário de, no máximo, seis armas. A partir da década de 1980, passou a ser questão central o controle social da arma, em função do aumento da criminalidade e dos níveis de violência. Os órgãos de segurança diagnosticaram a necessidade de atualizar, especificar melhor e endurecer a legislação, o que deu origem às primeiras discussões e projetos de aprimoramento do controle armamentício no Congresso Nacional.

Após uma década de discussões e propostas, o Congresso Nacional sancionou a Lei $n^{\circ}$ 9.437, de 20 de fevereiro (1997), que criou o Sistema Nacional de Armas (Sinarm), incumbido do cadastro de armas produzidas, importadas e vendidas no Brasil, além de definir crimes e dar outras providências formais. A promulgação dessa Lei significou um grande avanço no cenário do controle de armas brasileiras, pois foi a primeira a dispor sobre o uso de armas por civis e a estabelecer que tanto esse controle quanto o cadastro do que era produzido, vendido e importado seriam exercidos pelo Ministério da Justiça (e não de maneira pulverizada pelas autoridades policiais do país).

Em 22 de dezembro de 2003, surgiu a Lei no 10.826 (2003), que instituiu o Estatuto do Desarmamento. Essa Lei Federal, regulamentada pelo Decreto no 5123 
de 1 de julho de 2004, dispôs sobre registro, posse e comercialização de armas de fogo e munição, e criou normas mais rígidas para acesso a armas no Brasil. Houve, assim, a definição de requisitos que precisavam ser cumpridos para acesso à arma, dentre eles, a necessidade de comprovação de aptidão psicológica.

O Estatuto do Desarmamento determinou que somente o Departamento de Polícia Federal (DPF) teria autoridade para definir se uma pessoa pode ou não portar uma arma de fogo e ter seu registro. Quanto ao atestado de aptidão psicológica, seria exigido um laudo conclusivo necessariamente emitido por psicólogo do quadro da PF ou psicólogo por esta autorizado, por meio de credenciamento formal. Conforme Resende (2017), pela ausência de profissionais suficientes para dar conta da demanda, a PF iniciou o credenciamento formal de psicólogos e estabeleceu as primeiras orientações sobre o que e como deveriam ser avaliados.

Importante ressaltar que andar armado tornou-se ato proibido para civis, com exceções previstas na lei, tais como: Forças Armadas; órgãos policiais, incluindo agentes penitenciários; guardas municipais, respeitando os limites de habitantes de cada município; moradores de áreas rurais que precisassem de arma de fogo para caçar; e categorias com leis específicas, como juízes, promotores e atletas praticantes de tiro. Neste contexto, a avaliação psicológica dos órgãos de segurança pública já ocorria, regulada por normas específicas de cada uma das instituições. O conhecimento científico e o desenvolvimento de técnicas e métodos sobre avaliação psicológica avançou muito neste período, considerando a grande relevância e impacto do preenchimento de cargos no contexto da segurança pública brasileira.

A partir da edição do Decreto Federal no 5.123 de 1 de julho de 2004, a Diretoria Executiva do DPF publicou a Ordem de Serviço (OS) $\mathrm{n}^{\circ}$ 001, que estabeleceu normas da aferição de avaliação psicológica para aquisição e porte de arma de fogo para o Sistema Nacional de Armas. A OS definiu o perfil psicológico, o ambiente de aplicação, o processo de aplicação e correção de instrumentos, bem como a elaboração de laudos. Neste documento, foram exigidos como instrumentos da avaliação psicológica: um inventário de personalidade, um questionário, um teste projetivo, um teste expressivo, o módulo de informações complementares e a dinâmica de grupo, visando aferir a estrutura da personalidade. Previa-se, ainda, que um candidato considerado inapto poderia realizar uma reavaliação após 90 dias. Em 2005, foi editada, pelo DPF, a Instrução Normativa (IN) no 23/2005 (Departamento de Polícia Federal, 2005) que regulamentou a aptidão psicológica para manuseio de arma de fogo, indicando que o laudo, o credenciamento dos profissionais e a bateria de instrumentos de avaliação psicológica seriam definidos em um Manual do Psicólogo, entregue pela PF quando da indicação ou credenciamento dos profissionais.

Em março de 2013, instituiu-se a IN no 70/2013 (Departamento de Polícia Federal, 2013). Tal documento estabeleceu procedimentos para o credenciamento e a fiscalização de psicólogos responsáveis pela expedição de comprovante de aptidão psicológica para o manuseio de arma de fogo e regulamentou a atuação do psicólogo na avaliação psicológica do profissional vigilante. Foi estabelecida uma bateria de instrumentos, embora sem definir um perfil profissiográfico para o cargo de vigilante.

\section{Objetivo da avaliação psicológica para porte de arma de fogo}

Conforme anteriormente apresentado, o Decreto $\mathrm{n}^{\circ}$ 5.123, de 1 de julho de 2004, validou a prática do psicólogo em termos de normas e procedimentos a serem adotados no processo de avaliação psicológica. Por meio do Sinarm, foi estabelecido, como objetivo da avaliação psicológica, a definição de aptidão, ou inaptidão, de pessoas em portar arma de fogo. Nesta avaliação, não é possível predizer a ocorrência de um comportamento violento futuro (Madeira, Siminovich, \& Chardosim, 2011), mas possíveis indicadores de agressividade, impulsividade, emotividade, bem como outros requisitos psicológicos que tornem o indivíduo apto ou não.

O procedimento a ser seguido pelos psicólogos, no momento em vigência, é a IN no 78 , de 10 de fevereiro de 2014 (Departamento de Polícia Federal, 2014). Essa Instrução estabeleceu que psicólogos devem considerar as características de personalidade definidas para o usuário de arma de fogo e para o vigilante, conforme os Anexos V (Extrato dos Indicadores Psicológicos do Portador de Arma de Fogo) e VI (Extrato do Perfil Profissiográfico do Vigilante). Estes indicadores foram descritos como aptidão psicológica do interessado no manuseio de arma de fogo, a ser comprovada por meio da submissão à bateria de instrumentos de avaliação, composta por testes projetivos, testes expressivos, testes de atenção e de memória, bem como à entrevista semiestruturada. 
O CFP também estabeleceu na Resolução no 18/2008 e, posteriormente, na Resolução no 2/2009 (Conselho Federal de Psicologia, 2009), quais são as orientações da atuação do psicólogo no contexto da avaliação para porte de arma de fogo. Na segunda publicação do CFP, houve a alteração de dois artigos na Resolução. Foi restringido o vínculo de psicólogos em empresas deste contexto e a necessidade de uma entrevista devolutiva dos dados. Conforme Nota Técnica (NT) no 004/2019 do Conselho Regional de Psicologia do Paraná, foi indicada a "impossibilidade de que o(a) Psicólogo(a) realize a avaliação psicológica para porte de arma dentro das escolas, empresas de vigilantes, clubes de tiros ou locais que possam interferir a autonomia profissional da(o) Psicólogo(a) ou duplicar seu vínculo" (p. 3). Importante ressaltar que o vínculo não se limita apenas à questão trabalhista, por meio de contrato formal de trabalho. Conforme a NT (Conselho Regional de Psicologia do Paraná, 2019), "a sublocação de salas ou o desenvolvimento do trabalho nestes espaços também configura infração ética" (p. 3). Com base em todas as orientações prescritas, os psicólogos que trabalham no contexto da avaliação psicológica para porte de arma de fogo têm em mãos as orientações técnicas necessárias. Contudo, como toda avaliação psicológica compulsória, essa área tem enfrentado desafios recentes com a publicação de diferentes decretos normativos do poder público federal.

Desde 2019, foram publicados mais de 30 atos normativos, que vêm construindo a política armamentista no país. Em 12 de fevereiro de 2021, foram editados quatro novos Decretos: no 10627, no 10.628, no 10.629 e no 10.630 , em alteração aos de número 9.845, 9.846 e 9.847, de junho de 2019, e o Decreto no 10.030, de setembro do mesmo ano. Dentre as principais alterações estão, por exemplo, o aumento do número de armas de fogo que uma pessoa pode comprar (passou de quatro para até seis armas), o fato de os atiradores poderem adquirir até 60 armas de fogo e caçadores até 30 , bem como uma ampliação na quantidade de munição que pode ser adquirida para armas permitidas.

Além disso, foi proposta uma dispensa da obrigatoriedade de que colecionadores, atiradores e caçadores (CACs) apresentassem laudo psicológico emitido por profissionais psicólogos credenciados pela Polícia Federal. Bastaria que o laudo fosse elaborado por psicólogos sem formação específica, desde que devidamente inscrito e com o registro ativo nos Conselhos Regionais de Psicologia. Até o momento, o Decreto se encontra suspenso, por diferentes questionamentos sobre o seu mérito. Mas, o que isso tem a ver com o processo de avaliação?

Além dos decretos trazerem importantes implicações para a segurança do país, a maioria delas graves, na concepção de disseminar, de forma indiscriminada, o uso e a representação das armas de fogo, mais uma vez a Psicologia presencia a desqualificação de seu status científico e de sua atuação profissional por normativas externas, estabelecidas por campos de saber que parecem pouco conhecer da cientificidade da própria Psicologia. A tecnicidade desenvolvida na avaliação psicológica requer muito estudo e formação profissional contínua.

Para além desses desafios, é necessária uma conscientização dos psicólogos a respeito de sua responsabilidade nas avaliações psicológicas compulsórias. Ressalta-se a necessidade de um maior conhecimento técnico da área, principalmente buscando uma maior qualificação e especialização em termos de competências profissionais à atuação. É fundamental que os profissionais que trabalham no contexto das avaliações compulsórias reflitam sobre a amplitude e as consequências de sua decisão final, de aptidão ou não, referente ao uso da arma de fogo. Daí a enorme relevância da sua expertise e formação contínua técnico-profissional.

\section{Considerações finais}

Este artigo abordou, à luz de uma revisão na base legal normativa que embasa a realização da avaliação psicológica compulsória em concursos, características e aspectos éticos/técnicos relacionados à posse ou porte de armas de fogo no contexto brasileiro. Foram apresentados e discutidos alguns dos fatores complicadores, a maioria deles relacionados a questões de instruções normativas, leis e decretos do Governo Federal, que estão em descompasso com a prática profissional do psicólogo, impedindo que os profissionais atuem plena e eticamente na consecução desta atividade. Ainda, por meio de histórico legal, apresentaram-se algumas reflexões orientadas ao melhor embasamento da atuação do psicólogo neste campo, entendendo sua posição estratégica à realização de concursos que exigem avaliação psicológica compulsória. Não se pretendeu, aqui, esgotar o assunto em todas as suas possibilidades, mas apresentar inquietações que decorrem da prática do dia a dia em uma temática de tamanha relevância e impacto à sociedade brasileira. 
Quanto aos concursos, a grande questão que se coloca é que, apesar dos projetos de lei e debates existentes no Congresso Nacional, não existe, no Brasil, uma lei nacional (lei em sentido estrito) que regulamenta os concursos públicos de forma geral. Existem leis que tratam dos concursos de carreiras específicas (como policiais, juízes, Ministério Público, procuradores, advogados públicos, agentes penitenciários, entre outros), leis estaduais, decretos presidenciais e portarias do Ministério do Planejamento, Desenvolvimento e Gestão que tratam do assunto, mas não uma lei federal que estabeleça diretrizes gerais para a organização e realização de concursos públicos. Em decorrência da inexistência dessa "Lei Geral de Concursos Públicos", os certames têm sido balizados e influenciados de forma progressiva pela jurisprudência emanada do Poder Judiciário, principalmente pelas decisões emitidas pelas cortes superiores nacionais, no caso o STF e STJ, que têm impactado fortemente os concursos públicos realizados no país (Santos, n.d.).

O CFP tem realizado seu papel com a publicação de Resoluções que delimitam o fazer da avaliação psicológica nos diferentes contextos (como a Resolução no 2/2016 de concursos públicos), bem como orientações sobre a avaliação psicológica e seu instrumental (vide Resolução no 2/2018, atualmante em vigência). Contudo, as decisões dos Tribunais se sobrepõem ao resultado final da avaliação. Desconsiderar alguns encaminhamentos científicos dados à resolução dessa situação, como proposto por Santos (n.d.), pode levar à nulidade dos processos avaliativos, ocasionando, inclusive, críticas infundadas quanto à própria credibilidade e utilidade da Psicologia enquanto ciência e profissão. Importante ressaltar que tal fato não isenta profissionais psicólogos a seguirem as normativas do CFP sob a penalidade de sanções previstas no regulamento da sua profissão e, ainda, questionamentos formais do próprio judiciário, que também exigem esse cumprimento.
No contexto da avaliação para porte de arma, a ausência de um perfil científico definido e a falta de competência técnica por parte de alguns profissionais recai sobre uma das grandes preocupações indicadas por Messick (1995), que se refere às consequências sociais do uso e da interpretação do processo avaliativo. Noutras palavras, não se trata apenas de um simples resultado de apto ou inapto, mas das consequências que o resultado dessa avaliação poderá causar pelo uso adequado ou não da arma posteriormente, devido às possíveis implicações à vida humana e à sociedade como um todo. Isso indica que é imprescindível um preparo diferenciado desse profissional psicólogo, uma especialização técnica baseada na expertise necessária e a compreensão de um contexto muito mais macro dessa avaliação.

Nesse ínterim, torna-se imperiosa, também, a necessidade de se realizarem mais pesquisas científicas que possibilitem melhor compreensão e embasamento desse processo de avaliação psicológica compulsória, servindo como parâmetro para a discussão da prática do profissional psicólogo como um todo. Suscita-se um debate até mesmo sobre a abrangência e a própria qualidade da formação contida nos cursos de graduação em Psicologia espalhados pelo país no que tange, essencialmente, à preparação dos futuros profissionais à elaboração de processos de avaliação psicológica em contexto de avaliações compulsórias. O tema é amplo e extremamente complexo.

As pesquisas até então realizadas nos contextos de avaliação compulsória no Brasil ainda são escassas, revelando a necessidade de mais estudos e discussões científicas em função da melhoria nesse campo de atuação. É preciso compreender, inclusive, os impactos que a publicação de normativas provocam sobre os processos envolvidos na avaliação psicológica compulsória, bem como seus efeitos sobre a sociedade como um todo e as evidências de validade das avaliações ora realizadas.

\section{Referências}

American Psychological Association. (2001). Guidelines for test user qualifications. American Psychologist, 56(12), 1099-1113. https://doi.org/10.1037/0003-066X.56.12.1099

American Psychological Association. (2020). APA guidelines for psychological assessment and evaluation. APA. https://www.apa.org/about/policy/guidelines-psychological-assessment-evaluation.pdf

Aparecida, J. S., Mendes, D. F., \& Silva, L. A. M. (2018). Contribuições dos testes para a avaliação psicológica no trânsito. Psicologia e Saúde em Debate, 4(1), 9-43. https://doi.org/10.22289/2446-922X.V4N1A2

Boyle, S., Walsh, T., \& Nelson, L. (2021). A study into the operation of the queensland mental health review tribunal. Medical Law Review, fwaa043. https://doi.org/10.1093/medlaw/fwaa043 
Brasil. (1988). Constituição da República Federativa do Brasil de 1988. Presidência da República. https:// www.planalto.gov.br/ccivil_03/Constituicao/Constituicao.htm

Bueno, J. M. H., \& Peixoto, E. M. (2018). Avaliação psicológica no Brasil e no mundo. Psicologia: Ciência e Profissão, 38, 108-121. https://doi.org/10.1590/1982-3703000208878

Conselho Federal de Psicologia. (2003). Resolução CFP $n^{o}$ 002/2003. CFP. https://site.cfp.org.br/wp-content/ uploads/2012/05/resoluxo022003.pdf

Conselho Federal de Psicologia. (2008). Resolução CFP no 18/2008. CFP. https://site.cfp.org.br/wp-content/ uploads/2008/12/resolucao2008_18.pdf

Conselho Federal de Psicologia. (2009). Resolução CFP no 002/2009. CFP. https://site.cfp.org.br/wp-content/ uploads/2009/04/resolucao2009_02.pdf

Conselho Federal de Psicologia. (2018). Resolução CFP $n^{o}$ 009/2018. CFP. https://atosoficiais.com.br/lei/ avaliacao-psicologica-cfp?origin=instituicao

Conselho Federal de Psicologia. (2019). Avaliação psicológica compulsória [Número especial]. Revista Diálogos, 10, 1-53.

Conselho Federal de Psicologia. (2020). Ofício-Circular no 63/2020/GTec/CG-CFP: Recomendações do CFP sobre a elaboração de documentos psicológicos para o Poder Judiciário no contexto da pandemia do novo coronavírus. CFP. https://site.cfp.org.br/wp-content/uploads/2020/05/SEI_CFP-0221879-Of\%C3\%ADcio-Circular.pdf

Conselho Regional de Psicologia do Paraná. (2019). Nota Técnica CRP-PR no 004/2019. Orienta a(o) Psicóloga(o) na realização de avaliação psicológica para porte de arma de fogo. CRP-PR. https://crppr.org.br/nt-arma-de-fogo/

Decreto no 24.602, de 6 de julho de 1934. Brasil. (1934). http://www.planalto.gov.br/ccivil_03/Atos/decretos/1934/ D24602.html

Decreto $\mathrm{n}^{\circ}$ 1.246, de 11 de dezembro de 1936. Brasil. (1936). https://www2.camara.leg.br/legin/fed/ decret/1930-1939/decreto-1246-11-dezembro-1936-458789-publicacaooriginal-1-pe.html

Decreto no 47.587, de 4 de janeiro de 1960. Brasil. (1960). https://www2.camara.leg.br/legin/fed/decret/1960-1969/ decreto-47587-4-janeiro-1960-386925-publicacaooriginal-1-pe.html

Decreto no55.649, de28 de janeiro de 1965. Brasil. (1965). https://www2.camara.leg.br/legin/fed/decret/1960-1969/ decreto-55649-28-janeiro-1965-395863-publicacaooriginal-1-pe.html

Decreto no 5.123, de 1 de julho de 2004. Brasil. (2004). http://www.planalto.gov.br/ccivil_03/_Ato2004-2006/2004/ Decreto/D5123.htm

Departamento de Polícia Federal. (2005). Instrução Normativa no 23, de 1 de setembro de 2005. DPF. http://www. crpsp.org.br/portal/orientacao/manual/Instru\%C3\%A7\%C3\%A3o\%20Normativa\%2023-2005\%20-DG-DPF.pdf

Departamento de Polícia Federal. (2013). Instrução Normativa no 70, de 13 de março de 2013. DPF. http:// www.crprj.org.br/site/wp-content/uploads/2016/03/instrucaonormativaDPF70DE13.pdf

Departamento de Polícia Federal. (2014). Instrução Normativa no 78, de 10 de fevereiro de 2014. DPF. https:// www.gov.br/pf/pt-br/assuntos/armas/psicologos/instrucao-normativa_78_10defevereiro2014-1.pdf

Driskell, T., Salas, E., \& Driskell, J. E. (2018). Teams in extreme environments: Alterations in team development and teamwork. Human Resource Management Review, 28(4), 434-449. https://doi.org/10.1016/j.hrmr.2017.01.002

Esch, C. F., \& Jacó-Vilela, A. M. (2001). A regulamentação da profissão de psicólogo e os currículos de formação psi. In A. M. Jacó-Vilela, A. C. Cerezzo, \& H. B. C. Rodrigues (Orgs.), Clio-Psyché Hoje: Fazeres e dizeres psi na história do Brasil (2a ed., pp. 17-24). Centro Edelstein de Pesquisas Sociais.

Evans, F. B., \& Finn, S. E. (2016). Training and consultation in psychological assessment with professional psychologists: Suggestions for enhancing the profession and individual practices. Journal of Personality Assessment, 99(2), 175-185. https://doi.org/10.1080/00223891.2016.1187156

Faiad, C., \& Alves, I. B. (2018). Contribuições do Satepsi para avaliações psicológicas compulsórias (trânsito, porte de arma e concursos públicos) [Número especial]. Psicologia: Ciência e Profissão, 38, 50-59. https://doi. org/10.1590/1982-3703000208851

Faiad, C., Coelho Junior, F. A., Caetano, P. F., \& Albuquerque, A. S. (2012). Análise profissiográfica e mapeamento de competências nas instituições de segurança pública. Psicologia: Ciência e Profissão, 32(2), 388-403. https:// doi.org/10.1590/S1414-98932012000200009 
Gomez, V. A., Mazzoleni, M., Rodrigues, C. M. L., Bentes, A., Aquino, M. A., Torres, C. V., Nascimento, T., Oliveira, S. E. S., Chambel, M. J., \& Faiad, C. (2021). Conflito trabalho-família em segurança pública: Uma revisão integrativa. Revista SUSP, 1(1), 239-253.

Gregory, R. J. (2015). Psychological testing: History, principles, and applications. Pearson.

Hasbun, A. S. P. S, Formiga, N. S., \& Estevam, I. D. (2021). Z teste e tomada de decisão: Avaliação psicológica ideográfica para manuseio de arma de fogo. Research, Society and Development, 10(4), e5910413815. https:// doi.org/10.33448/rsd-v10i4.13815

Hochman, G. (1988). Aprendizado e difusão na constituição de políticas: A Previdência Social e seus técnicos. Revista Brasileira de Ciências Sociais, 3(7), 84-98.

Jesuíno, A. D. S. A., \& Rueda, F. J. M. (2017). Evidências de validade para testes de Impulsividade e Atenção no contexto do trânsito. Revista de Psicologia da IMED, 9(2), 24-41. https://doi.org/10.18256/2175-5027.2017.v9i2.1776

Lazzaretti, C. T. (2006). Transplantes de órgãos: avaliação psicológica. Psicologia Argumento, 24(45), 35-43. https:// doi.org/10.7213/rpa.v24i45.20019

Lei no 4.119, de 27 de agosto de 1962. Brasil. (1962). Casa Civil. www.planalto.gov.br/ccivil_03/LEIS/1950-1969/L4119.htm

Lei no 9.437, de 20 de fevereiro de 1997. Brasil. (1997). Casa Civil. https://www.planalto.gov.br/ccivil_03/Leis/L9437.htm

Lei no 10.826, de 22 de dezembro de 2003. Brasil. (2003). Casa Civil. https://www.planalto.gov.br/ccivil_03/ LEIS/2003/L10.826.htm

Madeira, C. A., Siminovich, M., \& Chardosim, N. (2011). Avaliação Psicológica para porte de arma de fogo. Entre Linhas, 6(55), 12. https://issuu.com/crprs/docs/abrilmaiojunho2011/3

Maia, M. B., \& Queiroz, R. P. (2007). O regime jurídico do concurso público e o seu controle jurisdicional. Saraiva.

Mancebo, D. (1999). Formação em psicologia: Gênese e primeiros desenvolvimentos. In A. M. Jacó-Vilela, F. Jabur, \& H. B. C. Rodrigues (Orgs.), Clio-Psyché: Histó rias da psicologia no Brasil (pp. 93-120). UERJ.

Martins, H. V. (2014). Uma história da psicologia em revista: Retomando Mira y López. Arquivos Brasileiros de Psicologia, 66(3), 5-19.

Mathews, R., \& Pratt, C. (2016). For the greater good: Protection of psychological test material. Psychiatry, Psychology and Law, 23(6), 842-848. https:// doi.org/10.1080/13218719.2016.1155510.

Messick, S. (1995). Validity of psychological assessment: Validation of inferences from persons responses and performances as scientific inquiry into score meaning. American Psychologist, 50(9), 741-749. https:// doi.org/10.1002/j.2333-8504.1994.tb01618.x

Ministério da Justiça. (1980). Portaria Ministerial no 1.261, de 11 de outubro de 1980. http://www.geocities.ws/ francoatiradorwp/legislacao3.html

Morel, K. R. (2009). Test security in medicolegal cases: proposed guidelines for attorneys utilizing neuropsychology practice. Archives of Clinical Neuropsychology, 24(7), 635-646. https://doi.org/10.1093/arclin/acp062

Muniz, M. (2017). Competências e cuidados para a administração da avaliação psicológica e dos testes psicológicos. In M. R. C. Lins \& J. C. Borsa (Orgs.), Avaliação psicológica: Aspectos teóricos e práticos (pp. 100-114). Vozes.

Muniz, M. (2018). Ética na avaliação psicológica: Velhas questões, novas reflexões [Número especial]. Psicologia: Ciência e Profissão, 38, 133-146. https://doi.org/10.1590/1982-3703000209682

Nunes, M. F. O., Muniz, M., Reppold, C. T., Bueno, J. M. H., Faiad, C., \& Noronha, A. P. P. (2012). Diretrizes para o ensino de avaliação psicológica. Avaliação Psicológica, 11, 309-316.

Oliveira, K. L., Monteiro, A. L., Faiad, C., Muniz, M., \& Schelini, P. W. (2020). Por que os professores diferenciam avaliação psicológica e testagem psicológica? In K. L. Oliveira, P. W. Schelini, \& S. M. Barroso (Orgs.), Avaliação psicológica: Guia para a prática profissional (pp. 11-20). Vozes.

Ostapovich, V., Barko, V., Okhrimenko, I., Yevdokimova, O., Ponomarenko, Y., Prontenko, K., Antonova, O., Sydorchuk, N., Sokolovskyi, O., \& Bloshchynskyi, I. (2021). Psychological profile of successful criminal police officer. International Journal of Applied Exercise Physiology, 9(3), 2322-3537. https://doi.org/10.26655/IJAEP.2020.3.27Rafalski, J. C., \& Andrade, A. L. (2015). Prática e formação: Psicólogos na peritagem em porte de arma de fogo. Psicologia: Ciência e Profissão, 35(2), 599-612. https://doi.org/10.1590/1982-370301472013 
Resende, M. A. (2017). Avaliação psicológica para concessão do porte de arma de fogo à população e policiais da PMMG. Revista Psicologia: Saúde Mental e Segurança Pública, 3(6), 113-131.

Rodrigues, C., \& Faiad, C. (2018). Avaliação psicossocial no contexto das normas regulamentadoras do trabalho: Desafios e práticas profissionais. Psicologia Revista, 27(2), 287-310. https://doi.org/10.23925/2594-3871. 2018v27i2p287-310

Santos, A. P. (n.d.). O papel do judiciário e sua influência no processo de avaliação psicológica. In C. Faiad (Org.), Avaliação psicológica em concursos públicos. Vetor.

Santos, A. P. (2016). Effects of legal judgments on psychological evaluations in the Brazilian federal police. Policing, 10(2), 113-120. https://doi.org/10.1093/police/pav053

Schneider, E. (1955). Normas para unificação de uma terminologia básica em Psicotécnica. Arquivos Brasileiros de Psicotécnica, 7(4), 17-22.

Sousa, A. R. S. (2011). O processo administrativo do concurso público [Dissertação de mestrado, Universidade Federal de Uberlândia]. Biblioteca Digital de Teses e Dissertações da UFU. https://repositorio.ufu.br/bitstream/123456789/13186/1/d.pdf

Superior Tribunal Federal. (2021). Ação direta de inconstitucionalidade 3481. STF. https://stf.jusbrasil.com.br/ jurisprudencia/1189594735/acao-direta-de-inconstitucionalidade-adi-3481-df-0001758-5220051000000/ inteiro-teor-1189594755

Szöke, H., Bókkon, I., Kapócs, G., Vagedes, J., Saahs, C., Mérey, A., \& Kovács, Z. (2018). Assisted reproductive 783 technology: Stress-related epigenetic and neurodevelopmental risk? Activitas Nervosa Superior, 60, 95-106. https://doi.org/10.1007/s41470-018-0026-3

Thadeu, S. H., Ferreira, M. C., \& Faiad, C. (2012). A avaliação psicológica em processos seletivos no contexto da segurança pública. Avaliação Psicológica, 11(2), 229-238.

Walter, F. A., Hoyt, T., Martinez, H., Dziura, J. (2021). Preoperative Psychological Assessment and weight loss outcomes in bariatric surgery patients at a military treatment facility: A retrospe ctive profile analysis. Military Medicine, usab078. https://doi.org/10.1093/milmed/usab078

\section{Cristiane Faiad}

Psicóloga com pós-doutorado pela Universidade de Lisboa. Doutora em Psicologia Social, do Trabalho e das Organizações pela Universidade de Brasília (UnB). Professora adjunta do Departamento de Psicologia Clínica e do Programa de Pós-Graduação em Psicologia Social, do Trabalho e das Organizações, da UnB. Coordenadora do Centro de Pesquisa e Tecnologias Sociais (cepats), da UnB, Brasília - DF. Brasil.

E-mail: crisfaiad@gmail.com

(1) https:// orcid.org/0000-0002-8012-8893

\section{Andersson Pereira dos Santos}

Delegado da Polícia Federal. Doutor em Administração pelo Programa de Pós-Graduação em Administração da Universidade de Brasília (UnB). Coordenador da Coordenação de Recrutamento e Seleção (Corec) da Polícia Federal, Brasília - DF. Brasil.

E-mail: anderssonpereira@hotmail.com

(1) https://orcid.org/0000-0002-1266-1418

\section{Elza Maria Gonçalves Lobosque}

Psicóloga. Mestre em Psicologia pelo Programa de Pós-Graduação da Universo - RJ. Professora do Centro Universitário Estácio de Juiz de Fora. Conselheira e coordenadora da Comissão de Orientação em Avaliação Psicológica do Conselho Regional de Psicologia de Minas Gerais. Coordenadora da Pós-Graduação em Avaliação Psicológica do Iespe, Juiz de Fora - MG. Brasil.

E-mail: elza.staffconsultoria@gmail.com

(1) https://orcid.org/0000-0002-8706-1839 


\section{Olavo Sant’Anna Filho}

Psicólogo. Doutor em Ciências Policiais de Segurança e Ordem Pública pelo Centro de Estudos Superiores da Polícia Militar de São Paulo. Especialista em Avaliação Psicológica. Conselheiro Nacional da Cruz Vermelha Brasileira. Credenciado da Polícia Federal, São Paulo - SP. Brasil.

E-mail: olavopsy@gmail.com

(i) https://orcid.org/0000-0001-7767-620X

\section{Lyani Vieira do Prado}

Psicóloga. Especialista em Avaliação Psicológica e em Psicologia do Trânsito. Psicóloga Voluntária do Serviço de Equoterapia da Polícia Militar de São Paulo. Credenciada da Polícia Federal, São Paulo - SP. Brasil.

E-mail: lvp8862@gmail.com

(D) https://orcid.org/0000-0001-7795-6703

\section{Francisco Antônio Coelho Junior}

Psicólogo com pós-doutorado pelo Instituto de Psicologia de Lisboa (Ispa). Doutor em Psicologia Social, do Trabalho e das Organizações pela Universidade de Brasília (UnB). Professor do Departamento de Administração e do Programa de Pós Graduação em Administração da Universidade de Brasília, Brasília - DF. Brasil.

E-mail autor: fercoepsi@gmail.com

(D) https://orcid.org/0000-0002-1820-5448

Endereço para envio de correspondência:

Universidade de Brasília. Campus Universitário Darcy Ribeiro, ICC Sul, Instituto de Psicologia, sala A1033. Asa

Norte. CEP: 70910-900. Brasília - DF. Brasil.

Recebido 04/06/2021

Aceito 04/06/2021

Received 06/04/2021

Approved 06/04/2021

Recibido 04/06/2021

Aceptado 04/06/2021

Como citar: Faiad, C., Santos, A. P., Lobosque, E. M. G., Sant’Anna Filho, O., Prado, L. V., \& Coelho Junior, F. A. (2021). Avaliação psicológica em concursos públicos e porte de arma: Histórico e desafios. Psicologia: Ciência e Profissão, 41, 1-13. https:// doi.org/10.1590/1982-3703003252456

How to cite: Faiad, C., Santos, A. P., Lobosque, E. M. G., Sant'Anna Filho, O., Prado, L. V., \& Coelho Junior, F. A. (2021). Psychological assessment in civil service entrance examination and firearm gun: History and challenges. Psicologia: Ciência e Profissão, 41, 1-13. https://doi.org/10.1590/1982-3703003252456

Cómo citar: Faiad, C., Santos, A. P., Lobosque, E. M. G., Sant’Anna Filho, O., Prado, L. V., \& Coelho Junior, F. A. (2021). Evaluación psicológica en competencias y la portación de armas: Historia y desafíos. Psicologia: Ciência e Profissão, 41, 1-13. https:// doi.org/10.1590/1982-3703003252456 